Journal of Applied Fluid Mechanics, Vol. 2, No. 2, pp. 69-75, 2009.

Available online at www.jafmonline.net, ISSN 1735-3572, EISSN 1735-3645.

DOI: $10.36884 /$ jafm.2.02.11871

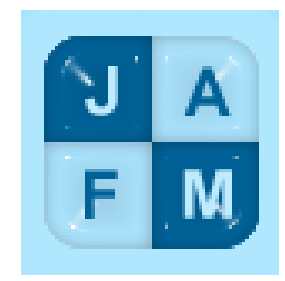

\title{
Impact of the Automotive Aerodynamic Control on the Economic Issues
}

\author{
A. Kourta ${ }^{1}$ and P. Gilliéron ${ }^{2}$ \\ ${ }^{1}$ ESA/Institut PRISME, Polytech'Orléans 8, rue Léonard de Vinci, 45072 Orléans France \\ ${ }^{2}$ Renault, Direction de Recherche, EA \& M, 1, Avenue du Golf, 78288 GUYANCOURT Cedex \\ Email: azeddine.kourta@univ-orleans.fr
}

(Received December 29, 2008; accepted February 12, 2009)

\begin{abstract}
Sustainable development associated with the need to reduce the energy consumption and to offer more creative freedom to the automobile designers requires looking for new solutions of control without appendix added nor geometrical modification. Among these solutions, the active flow control by fluidic actuators constitutes an interesting alternative. Various configurations of control are thus tested in order to reduce the aerodynamic drag. The results show that protocols based on control by suction, blowing or intermittent jet allows reducing the aerodynamic drag and consequently the consumption and $\mathrm{CO}_{2}$ emissions.
\end{abstract}

Keywords: Road vehicle, drag reduction, passive control, active control.

\section{NOMENCLATURE}

$\begin{array}{ll}H_{A} & \text { height of the Ahmed body } \\ L_{A} & \text { length of the Ahmed body } \\ H & \text { height of the Ahmed body base } \\ L & \text { width of the Ahmed body base } \\ l & \text { length of the rear window } \\ e & \text { width of the actuator slot } \\ C_{p} & \text { pressure coefficient } \\ C_{x} & \text { drag coefficient } \\ \Delta C_{x} & \text { drag coefficient reduction } \\ C_{\mu} & \text { momentum coefficient } \\ F_{k} & \text { flow characteristic frequency } \\ F_{j} & \text { synthetic jet frequency }\end{array}$

\section{INTRODUCTION}

The warming of planet is obviousness today. A growing number of observations indicates that the planet is heated (GIEC, 2001): During the 20th century, the temperature on the surface of the ground increased approximately by $0.6^{\circ}$, the snow-covered and the glacial extents were reduced approximately by $10 \%$ and the total mean level of the sea rose several tens of centimeters. According to the conclusions of the 3rd report of the Intergovernmental Group of expert on the Evolution of Climate (GIEC) of 2001, the human activity became in second half of the 20th century the first cause of increase in greenhouse gases effect and average temperature.

Without any energetic ecological measurements, global warming will continue and will accelerate during XXI century. Thus the amplitude of global warming is still

$\begin{array}{ll}F+ & \text { non dimensional frequency } \\ S_{1} & \text { wake section without splitter plate } \\ S_{2} & \text { wake section with splitter plate } \\ V_{0} & \text { free stream velocity } \\ V_{S} & \text { suction velocity } \\ V_{B} & \text { blowing velocity } \\ V_{j} & \text { synthetic jet velocity } \\ \mathrm{x} & \text { longitudinal coordinate } \\ \mathrm{y} & \text { transverse coordinate } \\ \mathrm{Z} & \text { lateral coordinate } \\ h & \text { height } \\ \alpha & \text { rear window angle }\end{array}$

the subject of debates, the atmospheric average temperature for the fifty nearest years will increase and this increase could be in the range of $+1,8$ to $+4^{\circ} \mathrm{C}$. The consequences will be considerable on the environment and civilization. On the environment, the impoverishment of the biodiversity and the more frequently destructive climatic phenomena are to be considered. On the civilization, the experts foresee an important reduction of the water resources in the tropical and subtropical dry areas as well as the extension of the areas infested by certain diseases, such as the cholera. The exploratory studies show that an ambitious reduction known as of a "factor 4" of the gas emissions with greenhouse effect will concern all the industrial branches: building, transport, materials... to limit global warming. In France, through the law on the ecology of 2005 , commits itself to divide by four the national gas emissions with greenhouse effects before 2050 . 
Concerning the road vehicles, the world park counted in 2002 nearly 590 million units (SASI, 2008). In this context, the annual $\mathrm{CO}_{2}$ emissions exceed already the 22 billion tons whereas the requirements in transport vehicles for the emergent countries increase. As an example, the demand for fossil energy of China and India transforms today the world energy system which becomes incompatible with the available resources and the need for reducing the gas emissions with greenhouse effect. The Chinese car park could thus count in 20 years nearly 270 million vehicles, that is to say thirty times more than in 2002. Eastern Europe and Africa follow the same process in more or less equivalent proportions and in short or long term. In this context, the gas emissions with greenhouse effect will increase closely of $57 \%$ in 2030 with strong effects on the environment and the climate (IEA, 2007). In Europe, The European Community Council has defined a $\mathrm{CO}_{2}$ emission limitation for 2012. In fact, the gas emissions of the motor vehicles will not have to exceed 120 gr. per kilometer. This limitation could be undoubtedly 90 gr. in 2018. For the customer and 100 kilometers to $130 \mathrm{~km} / \mathrm{h}$, the result must allow to reduce the fuel consumption of a vehicle of the range M1 (vehicle of the lower average range) of approximately 1.6 liters. Particularly significant progress was already obtained on the outputs of the engines and the interesting prospects identified as for the use of the biofuel. Significant progress is still possible by reducing the mass, rolling friction or aerodynamic drag.

Concerning aerodynamics, the work carried out for more than 15 years and the progress made on the understanding of the physical phenomena allows considering the possibility of solutions in rupture. The reductions of aerodynamic drag associated with the contracting of air intake, with the increase in the pressure losses of the exchangers, with the vertical extension of the low part of the front bumper or with the presence of a deflector positioned before of the rear wheel-axle unit are thus better understood and used with more effectiveness, Chometon et al. (1996). Integral momentum approaches allows identifying solutions to reduce the contribution of the engine compartment in aerodynamic drag and to improve the effectiveness of the exchangers, (Gilliéron and Chometon 2001, Ivanic and Gilliéron 2005, Chometon and Gilliéron 1998). The flows near the wall are described by mathematical models to improve comprehension of the portraits of phases raised during parietal visualizations (Gilliéron and Chometon 1999) and to identify solutions intended to reduce the contribution of separations in total aerodynamic drag. All these results can then be used to conceive new solutions and to develop solutions able to reduce at least $20 \%$ aerodynamic drag in the 5 next years. On the normalized course NEDC (for New European Driving Cycle), the reduction of the $\mathrm{CO}_{2}$ emissions would be about $0.7 \mathrm{~kg}$ for 100 kilometers or 7 grams per kilometer.

\section{SPECification of the Problem}

A road vehicle is a short lengthening body which moves near the ground in a naturally turbulent flow. The flow separation occurs everywhere around a vehicle: at the air intake, around the wheel, on the base, to the both sides of the windscreen, on the rear window and at the base. The shear stress contribution on the total drag remains small, about $10 \%$, and the aerodynamic drag results mainly from the pressure distribution contribution particularly on the rear window and on the base. This contribution corresponds to $90 \%$ of total car aerodynamic drag and $80 \%$ of this contribution is due to the rear part.

The flow around the real road vehicle is complex and presents nonlinear interactions between different parts of the vehicle. To perform effective control solution reducing drag it is efficient to work on simplified geometries able to reproduce the physical phenomena met on a real vehicle. The geometry suggested by Ahmed et al. (1984) allows to reproduce these phenomena (Fig. 1) and thus to develop and to evaluate control solutions.

On this geometry, the flow separates at the end of the roof and attaches on average at the bottom of the rear window. The separated flow is the seat of two contra rotating movements which converge towards two separation focuses (Gilliéron and Chometon 1999 and Ahmed et al. 1984). The flow resulting from these two focuses interacts and feeds then the base flow. Part of the flow resulting from the side parts of the geometry separates on the side of the rear window and creates two contra rotating longitudinal swirling structures. At the base, the flow separates at the periphery to generate a torus swirling structure which interacts with the separated flow of the rear window. This complex topology can be modified using passive or active control systems.

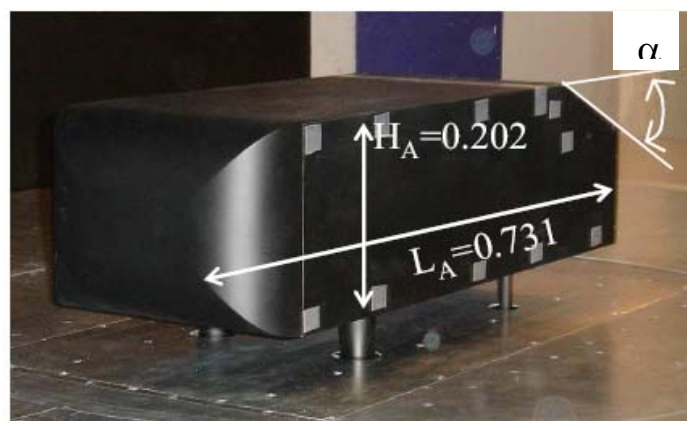

Fig. 1. Ahmed body (scale 0.7)

\section{Passive Control}

The passive control systems consist on the use of more or less discrete obstacles, added around or on the roof of the vehicle. They can be declined in 2 groups according to their influence on the flow control. The first group consists on obstacles positioned on the surface of the geometry. The second group consists of the obstacles positioned upstream or downstream of the geometry to be controlled.

Among the solutions based on obstacles positioned on the surface of the geometries, the Vortex Generators (VG), constitute particularly interesting solutions. The obstacles are triangular or rectangular elements positioned just before separation line. The longitudinal swirling structure resulting on the interaction with the flow field increases the kinetic energy transfer from the outside of the boundary layer towards the wall. Velocity 
near the wall increases and the separation position is moved downstream. Drag reductions of about $43 \%$ were thus obtained on a wing profile at the stall Bak et al. (2000). For the road vehicle this technique was tested by the manufacturers, some patents were deposited (Renault, PSA...) (Fig. 2) and drag reductions close to $8 \%$ were obtained. Obstacles positioned on surface can also be used to reduce the transverse extension of separated bubble (careenage of front face, of wheel) or to fix the separation line (flap). They can also be used to promote the flow separation in order to increase the static pressures on the rear window or on the base. They could be also used to reduce the alternate shedding of swirling structures.

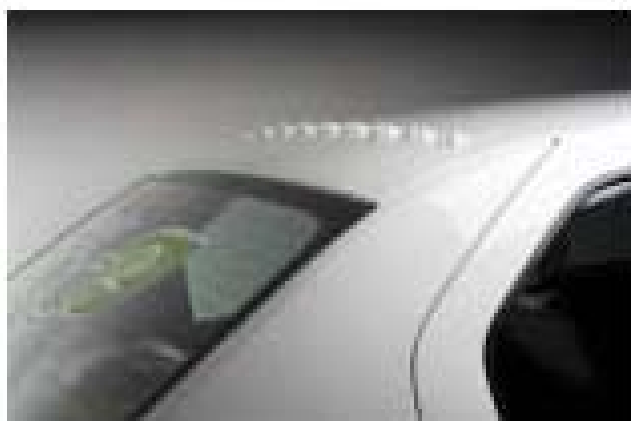

Fig. 2. Vortex generators on Logan Dacia/Renault, Renault (2007).

Significant drag reduction can also be obtained by adding vertical splitter plates upstream or downstream of the vehicle. Placed before the vehicle, these elements allow reducing transverse sizes of the wake, decreasing velocity near the separation line and increasing the static pressures at the base. Experiments performed in a wind tunnel on square back Ahmed body (Levallois and Gilliéron 2005) show that the transverse expansions of the wake can be reduced and hence the aerodynamic drag. Drag reduction close to $11.6 \%$ have been obtained. In Fig. 3, the rectangular splitter plate is positioned at 0,7 $\mathrm{H}$ from the base, where $\mathrm{H}$ represents the height of the base. The splitter plate surface is $0,9 \mathrm{H} * 0,85 \mathrm{~L}$ where $\mathrm{L}$ represents the width of the geometry.

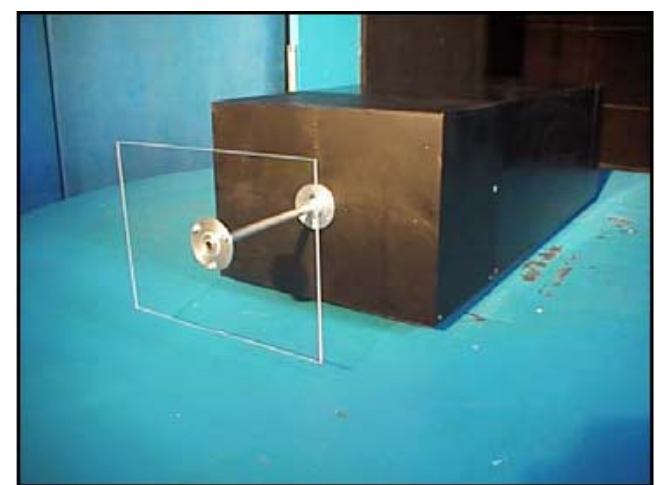

Fig. 3. Transverse splitter plate (Levallois and Gilliéron 2005)

The obtained results indicate a strong correlation between the drag value and the presence of a torus swirling structure at the base. The flow attaches at the periphery of the splitter plate, a torus swirling structure occurs at the base and the wake behind the splitter plates becomes like the one of the square back. The cross section S2 of the obtained wake is then lower than the S1 section of the wake behind a body without control.

Significant reductions can be also obtained by using longitudinal splitter plates positioned in prolongation of the base. The objective consists on creating a low velocity flow cavity in order to increase the static pressure at the base. This kind of solution is generally coupled with a wake surface reduction obtained by inclining the opposite longitudinal splitter plates. In this case, drag reductions close to $22 \%$ were obtained on a square back Ahmed body. Here, the splitter plates are fixed at the periphery of the base; the splitter plate length is equal to $0.13 \mathrm{H}$ (H height of the base) and inclined with 15 degrees from the incident airflow direction (Fig. 4). Khalighi et al. (2001) obtain 20\% drag reduction with the same device and hence confirm these results.

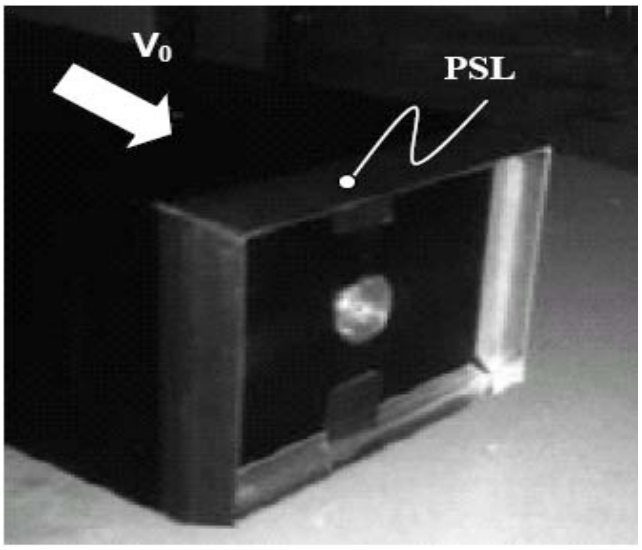

Fig. 4. Longitudinal splitter plate

\section{ACtive Control}

Active control is performed by using actuators that require a power generally taken on the principal generator of energy of the vehicle. The visible part of these systems includes mobile walls, circular holes or slots distributed on the vehicle surface where the flow must be controlled. Their use requires mechanical, electromagnetic, electric, piezoelectric or acoustic systems placed in the hollow parts of the vehicle. Their weights and their overall dimensions must be smallest as possible to reduce their impacts on consumption and habitable volume. Several control solutions have been identified, tested and analyzed for aeronautics. It has been the same for the hydrodynamic and the aerodynamic of the road vehicles. The adopted solutions generally consist on suction or blowing systems through circular or rectangular slots. The suction and blowing can be continuous or intermittent.

\subsection{Active Control: Steady Suction}

Suction is used to control separation on a rear window of Ahmed body inclined with $25^{\circ}$. After optimization of the various parameters (position, width, suction intensity and orientation,...), significant drag reductions have been observed. Drag reductions close to $18 \%$ were obtained (Rouméas et al. 2005, 2008) for a suction velocity Vs equal to 0.6 times the inlet farfield velocity. The 
separation at the end of the roof is suppressed and the static pressure coefficients on the rear window and on the base changes significantly. On the rear window, the static pressure coefficients decrease and increase gradually until reaching values higher than the values obtained without control (Fig. 5). At the base, control by suction tends to smooth the static pressures variation and to increase its mean value (Fig. 6). These results were obtained both numerically and experiments (Rouméas 2006).

The suction allows to suppress the rear window separation (Fig. 7) and to decrease the aerodynamic drag. When the suction velocity is equal to $0.6 \mathrm{~V}_{0}$, more than $17 \%$ drag reduction can be obtained (Fig. 8).

The suction can also be used to reduce the aerodynamic drag contribution of the swirling longitudinal vortices appearing at the left and right side of the windscreen. Drag reductions close to $8 \%$ were thus obtained numerically and experimentally on a simplified geometry, Lehugeur and Gilliéron 2006 and Lehugeur 2007. This result is obtained for a suction direction normal to the side pane positioned immediately after the separation line and with a velocity equal to the upstream velocity. The slit are positioned on the height of the Apillar and the width of the slit is equal to $10^{-3} \mathrm{~m}$. The results show important modifications on the instantaneous parietal pressure distributions measured on side surfaces (side panes of the vehicle), Lehugeur and Gilliéron 2007. This last result constitutes an interesting prospect to decrease the aeroacoustic noise, to improve the dynamic stability of the vehicle or to reduce the dirt.

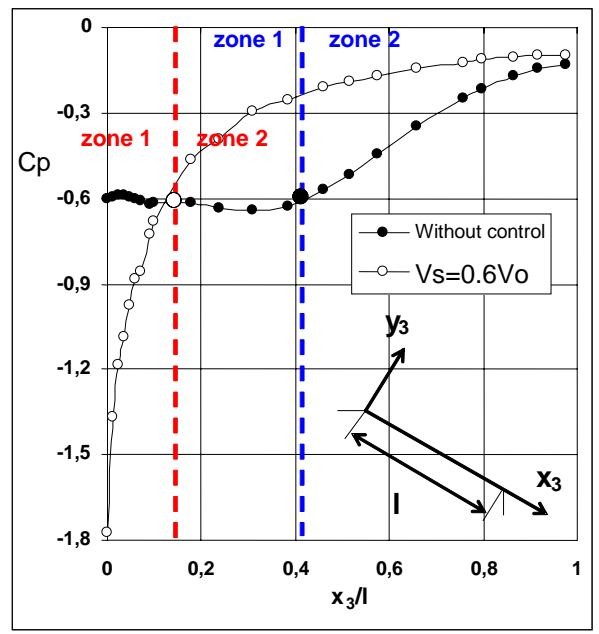

Fig. 5. Control effect on the rear window static pressure coefficients distribution

\subsection{Active Control: Continuous Blowing}

- Drag reductions can also be obtained by using a continuous blowing. In this case, blowing is used to dislocate or to breakdown the longitudinal swirling vortices of the rear window in order to increase the parietal static pressures and hence to reduce the aerodynamic drag (Lehugeur 2007).

Usually, the vortex breakdown is obtained by increasing the Swirl value (ratio between the azimuthal and axial velocities) up 1.5. It has been obtained by increasing the local azimuth velocity. Blowing is performed perpendicular to the rear window through a slot all along its height. The slot thickness is $\mathrm{e}=10^{-3} \mathrm{~m}$.

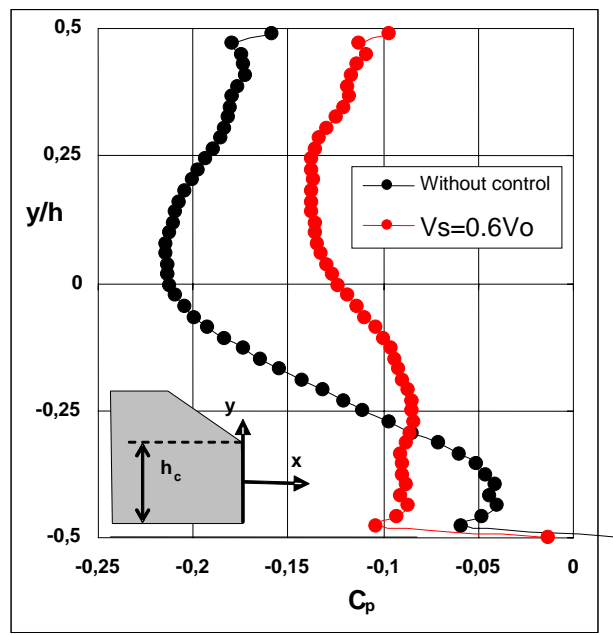

Fig. 6. Control effect on the base: distribution of the static pressure coefficient
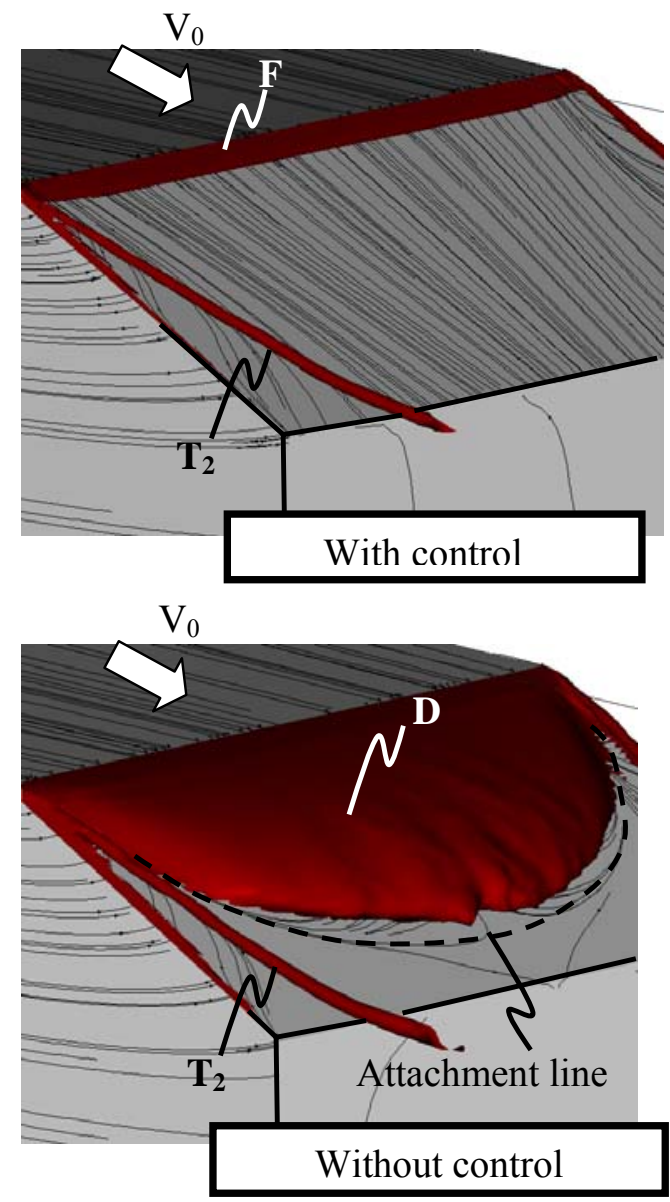

Fig. 7. Control effect on the rear window separation

The results obtained for blowing velocity $\mathrm{V}_{\mathrm{B}}=0.5 \mathrm{~V}_{0}, \mathrm{~V}_{0}$ and $1.5 \mathrm{~V}_{0}$ are compared to the case without control. Without control (Fig. 9a) the low values of the parietal 
static pressure coefficient $C_{\mathrm{P}}$, close to -1.2 , are observed under the axis of the swirling structure. With blowing (Figs. 9b, c and d) the coherence of the longitudinal vortices is not so evident $\left(C_{P} \sim-0.5\right)$ and the parietal static pressure coefficients increase when moving from the bottom to the top of the rear window. At the top of the rear window, the static pressure coefficients decrease with the blowing velocity. The minima of $\mathrm{C}_{\mathrm{P}}$ evolve from -1.1 without blowing to $-1.3,-1.4$ and -1.7 with blowing velocity respectively equal to $0,5 \mathrm{~V}_{0}, \mathrm{~V}_{0}$ and $1,5 \mathrm{~V}_{0}$. These results suggest the existence of an optimal value of blowing which allows to disorganize the swirl and to adapt the distribution of the static pressures from the top to the bottom of the rear window. The best drag reduction obtained is of about $6 \%$ corresponding to the blowing velocity $\mathrm{Vs}=0.5 \mathrm{~V}_{0}$. For a median vehicle (Renault Megane for example), the consumption decreases then by 0.4 liter per 100 kilometers at the car speed of $130 \mathrm{~km} / \mathrm{h}$. In this case, according to NEDC cycle, the emissions are reduced by 2.3 grams per kilometer.

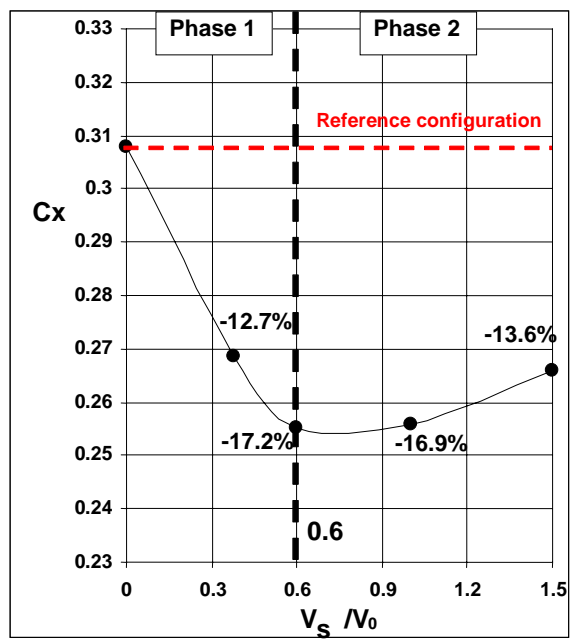

Fig. 8. Drag coefficient evolution with velocity ratio

\subsection{Active Control: Synthetic Jet}

The flow control by using fluidic actuators based both on blowing and suction offer interesting prospects in term of energy efficiency. The fluidic actuator can be pulsed or synthetic jet depending if the average of the exhaust flow rate during one period is respectively non zero or zero.

In the following, only recent results obtained in the case of the flow control by using a synthetic jet will be presented. Over one period $\mathrm{T}_{\mathrm{j}}$, the exhaust flow rate through the surface of the slot is null, while the momentum injected into the external flow is positive and without adding a mass. Moreover, the repetition of the suction and blowing phases allows to create unsteady structures in the flow and to increase the effectiveness of the control compared to stationary solutions such as the continuous suction or blowing.

The synthetic jet frequency is obtained from the characteristic scales. It can be defined by taking the height of the geometry as the length scale and as the
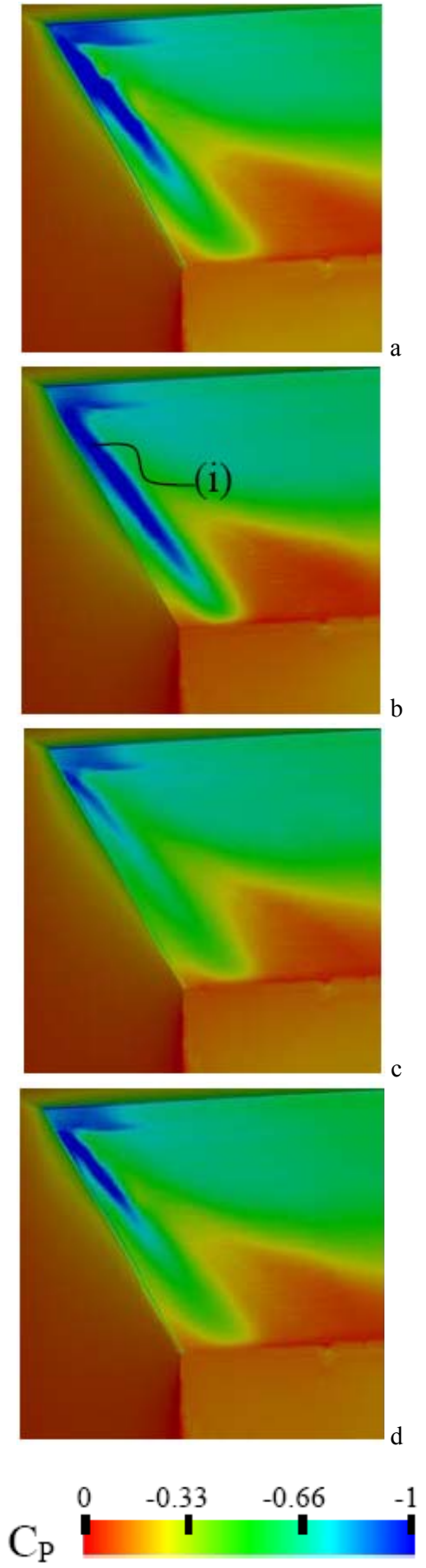

Fig. 9. Evolution of the drag coefficient with blowing velocity: a) Without blowing $\left(\mathrm{V}_{\mathrm{B}}=0\right)$, b) $\mathrm{V}_{\mathrm{B}}=0.5 \mathrm{~V}_{0}$, c) $\mathrm{V}_{\mathrm{B}}=\mathrm{V}_{0}$, and d) $\mathrm{V}_{\mathrm{B}}=1.5 \mathrm{~V}_{0}$ (Lehugeur 2007).

velocity scale the farfield velocity $\mathrm{V}_{0}=40 \mathrm{~m} \cdot \mathrm{s}^{-1}$. For these values and for classical road vehicles, the characteristic frequency $F_{k}$ is close to $140 \mathrm{~Hz}$. The momentum coefficient can be obtained from the body transversal section, the surface of the synthetic jet slot, the synthetic jet velocity amplitude and the inlet (or farfield) velocity $\mathrm{V}_{0}$. The ratio between the synthetic jet frequency $F_{j}$ and the characteristic frequency $F_{k}$ allows to define a reduced 
frequency $\mathrm{F}+=\mathrm{F}_{\mathrm{j}} / \mathrm{F}_{\mathrm{k}}$. (Leclerc et al. 2006, 2006b and Leclerc 2008).

Three-dimensional computations of Ahmed body with a synthetic jet positioned at the end of the roof (at $4.510^{-3}$ $\mathrm{m}$ in front of the top of the rear window), show a decrease of the aerodynamic drag when the momentum factor $\mathrm{C} \mu\left(C_{\mu}=e l V_{j}^{2} / H_{A} L_{A} V_{0}^{2}\right)$ increases up to a threshold value $\mathrm{C}_{\mu 0}$, see Fig. 10. The transverse development of the rear window separation decreases (Fig. 11), the flow evolution close to the wall is modified, the wake longitudinal vortices are more symmetric and the pressure at the base increases. Transverse vortices appear and are drove by the synthetic jet frequency. These vortices move towards the base and the longitudinal size of the rear window separation is reduced. For the tested cases and in accordance with the results obtained for the continuous blowing, the best drag reductions are obtained when the actuator is positioned at the top of the rear window close to the separation line. It can be observed that the slot position at the top of the rear window (downstream) is more efficient than at the roof (upstream) (Fig. 10). The maximum drag reduction obtained is close to $13 \%$ for the momentum factor equals to $\mathrm{C}_{0}$, Fig.10, Leclerc 2008 .

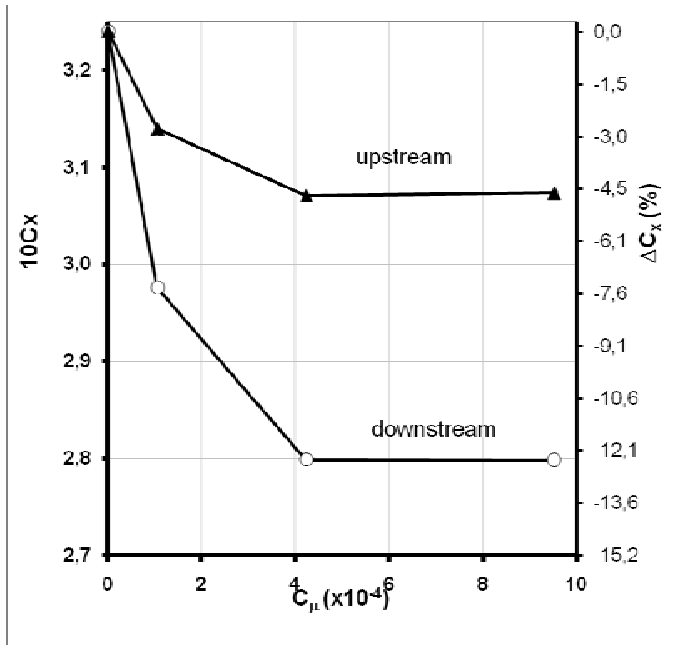

Fig. 10. Aerodynamic drag coefficient and percentage of drag reduction variation with $\mathrm{C}_{\mu}$ and for $\mathrm{F}+=0.7$.

\section{CONCLUSIONS}

This paper deals with a separation control to reduce consumption and the gas emissions to greenhouse effect of the future motor vehicles. After reviewing the passive control solutions, examples of active control by suction, blowing or by synthetic jet are successively presented. The results show the strong potential of the tested actuators. Work is in hand to improve their energy efficiency, to seek associations of control in various places of the vehicle and to develop actuators of low mass, of small overall dimensions to strong energetic efficiency. Drag reductions close to $30 \%$ are thus already considered without strongly modify the current car geometries in terms of habitability and comfort. The aerodynamic drag coefficients of the future motor vehicles intended for the urban extra connections could then tend very soon towards values close to 0.20 . This evolution would then allows to reduce by 2.4 liter per $100 \mathrm{~km}$ the average consumption of a vehicle (like Scénic type) on a highway at the speed of $130 \mathrm{~km} \cdot \mathrm{h}^{-1}$. The gas emission reduction would be at least about 12 grams per kilometer (NEDC cycle).

\section{ACKNOWLEDGMENT}

We wish to express many thanks to Dr. C. Leclerc, Dr. B. Lehugeur and Dr. Mr. Rouméas for their contributions in this work. This work has been done in the context of GDR 2502 "Contrôle Des Décollement” CNRS.

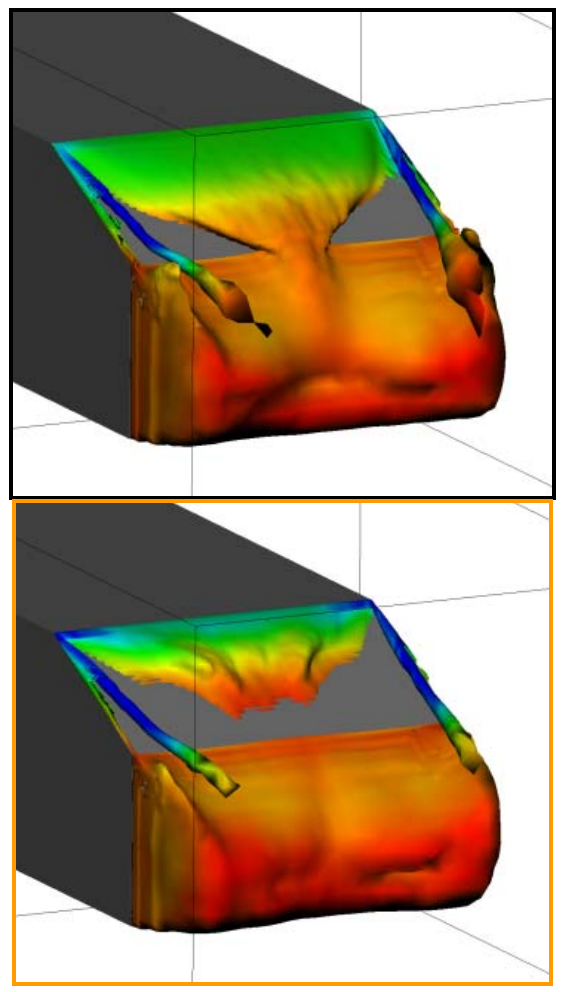

Fig. 11. Iso total pressure loss coefficients $(\mathrm{Cpi}=1)$ : without control (top), with control $\mathrm{C} \mu=9.810^{-4}$ (bottom) (Leclerc 2008).

\section{REFERENCES}

Ahmed S.R., G. Ramm and G. Faltin (1984). Some salient features of the time-averaged ground vehicle wake, SAE technical paper series, $n^{\circ} 840300$, Detroit.

Bak C., P. Fuglsang, J. Johansen and I. Antoniou (2000). Wind tunnel test of the NACA 63415 and amodified NACA 63415 Airfoil, Riso R-1193, Riso National Laboratory, Roskilde, Denmark.

Chometon F. and P. Gilliéron (1998, February). Assessment of engine cooling performance by measurement of cooling airflow drag in 
aerodynamic wind tunnels, SAE Congress, Detroit, Michigan, USA.

Chometon F. and P. Gilliéron (1996, November) Modélisation des écoulements tridimensionnels décollés autour desvéhicules automobiles, Congrès SIA, Société des Ingénieurs de l'Automobile, $n^{\circ}$ SIA 96-09-11, Courbevoie / Paris.

Gilliéron P. and F. Chometon (2001, March). Reduction of cooling air drag of road vehicle: an analytical approach, SAE paper $n^{\circ} 01 B-48$, SAE Congress, Detroit, Michigan, USA.

Gillieron P. and F. Chometon (1999). Modelling of stationary three-dimensional detached airflows around an Ahmed Reference Body, Third International Workshop on Vortex, ESAIM, Proceedings $7, \quad 173-182$, http://www.emath.fr/proc/Vol7.

Groupe d'experts Intergouvernemental sur l'Evolution du Climat (GIEC) (2001). "Bilan 2001 des changements climatiques : Les éléments scientifiques", 3èmerapport d'évaluation 2001, http://www.grida.no/climate/ipcc_tar/vol4/french/pd f/wg1sum.pdf.

IEA (2007). World Energy Outlook 2007, Executive Summary, China and India Insights, International Energy Agency IEA, ISBN: 978-92-64-02730-5.

Ivanic T. and P. Gilliéron (2005, April). Reduction of the aerodynamic drag to cooling systems: an analytical and experimental approach, SAE paper $n^{\circ} 2005-01$ 1017, SAE Congress, Detroit, Michigan, USA.

Khalighi B., S. Zhang, C. Koromilas., S.R. Balkanyi, L.P. Bernal, G. Iaccarino, and P. Moin (2001). Experimental and Computational Study of unsteady Wake Flow behind a Bluff Body with a Drag Reduction Device, SAE SP-1600, Detroit, Michigan.

Leclerc C. (2008, January) Réduction de la traînée d'un véhicule automobile simplifié à l'aide du contrôle actif par jet synthétique, thèse doctorat, Institut de Mécanique des Fluides de Toulouse.

Leclerc C., E. Levallois, P. Gilliéron and A. Kourta (2006, June). Aerodynamic Drag Reduction by Synthetic Jet: A 2D Numerical Study around a Simplified Car, 3rd AIAA Flow Control Conference, San Francisco, California.

Leclerc C., E. Levallois, P. Gilliéron, A. Kourta and Q. Gallas (2006). Phase Locked Analysis of a Simplified Car Geometry Wake Flow Control Using Synthetic Jet, ASME Joint U.S. - European Fluids Engineering Summer Meeting, paper $n^{\circ}$ FEDSM2006-98469, Miami, Florida.

Lehugeur B. and P. Gilliéron (2007, August). Analyse de l'influence du contrôle des tourbillons longitudinaux de montants de baie sur les champs de pression pariétale en aérodynamique automobile, 18ième Congrès Français de Mécanique, Grenoble, France.
Lehugeur B. (2007). Caractérisation et contrôle des structures tourbillonnaires longitudinales en aérodynamique automobile, thèse doctorat, Université Pierre et marie Curie.

Lehugeur B. and P. Gilliéron (2006, April). Drag reduction by active control of A-pillar vortex breakdown on a simplified car geometry, European Drag Reduction and Flow Control Meeting, Ischia, Italy.

Levallois E. and P. Gilliéron (2005, June). Réduction de traînée aérodynamique par contrôle passif des écoulements - analyse par PIV, Colloque de visualisation et de traitement d'images en mécanique des fluides (FLUVISU 11), EC Lyon.

M. Rouméas, P. Gillieron and A. Kourta (2008). Separated flows around the rear window of a simplified car geometry, Journal of Fluid Engineering 30(021101-1).

Renault (2007, October). Direction de la Communication, Communiqué de Press, A l'occasion du Challenge Bibendum Michelin, Renault présente Logan "Renault ECO2" concept, véhicule écologique et économique.

Rouméas M. (2006). Contribution à l'analyse et au contrôle des sillages de corps épais par aspiration ou soufflage continu, thèse doctorat, Institut National Polytechnique de Toulouse.

Rouméas M., P. Gilliéron and A. Kourta (2005, June). Analyze and control of the near-wake flow over simplified car geometry, 4th Conference on Bluff Body Wakes and Vortex-Induced, Vibrations (BBVIV4), Santorin, Greece.

SASI (2006). Passenger Cars, University of Sheffield and University of Michigan, Produced by SASI Group (Sheffield) and Mark Newmann (Michigan). 